\section{References}

1. Yamanaka O, Hobbs RE. Coronary artery anomalies in 126,595 patients undergoing coronary arteriography. Cathet Cardiovasc Diagn. 1990;21: 28-40.

2. Nakahira A, Sasaki Y, Hirai H, Fukui T, Motoki M, Takahashi Y, et al. Rupture of aneurysmal circumflex coronary artery into the left atrium after ligation of its arteriovenous fistula. Circ J. 2007;71:1996-8.
3. Loo B, Cox ID, Morgan-Hughes GJ, Marchbank AJ. Thrombotic occlusion of giant circumflex artery aneurysm after ligation of arteriovenous fistula. Circulation. 2010;122:e447-8.

4. Pettersson G, Norgaard MA, Arendrup H, Brandenhof P, Helvind M, Joyce F, et al Direct bronchial artery revascularization and en bloc double lung transplantation—surgical techniques and early outcome. J Heart Lung Transplant. 1997; 16:320-33.

\title{
Staged Kawashima operation with cavopulmonary connection
}

\author{
Yogesh Sathe, FNB, Shanthi Chidambaram, FNB, Krishna Manohar, MCh, and
}

Kotturathu Mammen Cherian, FRACS, Chennai, India

We herein present our technique of staging the Kawashima procedure in a child with single ventricle and interruption of the inferior vena cava (IVC) with fair-sized pulmonary arteries by creating a bidirectional cavopulmonary anastomosis first, followed by Fontan completion as the second stage.

\section{CLINICAL SUMMARY}

A 3.5-year-old girl weighing $10 \mathrm{~kg}$ with tricuspid atresia, ventricular septal defect, and pulmonary stenosis with fair-sized pulmonary arteries was taken for bilateral bidirectional cavopulmonary anastomosis on the basis of echo-

From the Department of Pediatric Cardiology and Cardiac Surgery, Frontier Lifeline and Dr K M Cherian Heart Foundation, Chennai, India.

Disclosures: Authors have nothing to disclose with regard to commercial support.

Received for publication Oct 26, 2011; revisions received Dec 17, 2011; accepted for publication Jan 4, 2012; available ahead of print Feb 13, 2012.

Address for reprints: Yogesh Sathe, FNB, Department of Pediatric Cardiology, R-30-C, Frontier Lifeline Hospital, Chennai, India (E-mail: satheyogesh74@ rediffmail.com).

J Thorac Cardiovasc Surg 2012;144:267-8

$0022-5223 / \$ 36.00$

Copyright (C) 2012 by The American Association for Thoracic Surgery

doi:10.1016/j.jtcvs.2012.01.007 cardiography in 2001. At surgery, absent right superior vena cava (SVC) and interrupted IVC with hemiazygos continuation to a large left SVC and joining of hepatic veins to the right atrium were noted. On cardiopulmonary bypass, the left SVC was divided above the hemiazygos vein and anastomosed to the left pulmonary artery as a left bidirectional Glenn shunt, leaving the IVC drainage unchanged. Because the pulmomary artery mean pressure was $18 \mathrm{~mm} \mathrm{Hg}$, the pulmonary trunk was banded to allow a limited antegrade flow (Figure 1, A) She made a good recovery but was lost to follow-up after 2 years.

She returned at the age of 13 years (2010) with progressive effort dyspnea and worsening cyanosis (arterial oxygen saturation, 72\%).A cardiac catheterization showed a wellflowing left-sided Glenn shunt and IVC drainage via the hemiazygos vein into the coronary sinus through the proximal left SVC (Figure 2). There were no pulmonary arteriovenous malformations or venovenous collaterals.

During Fontan completion, the hemiazygos vein was disconnected from the left SVC stump and anastomosed end to side to the left pulmonary artery, completing the Kawashima procedure. The hepatic veins were connected to the right pulmonary artery with an $18-\mathrm{mm}$

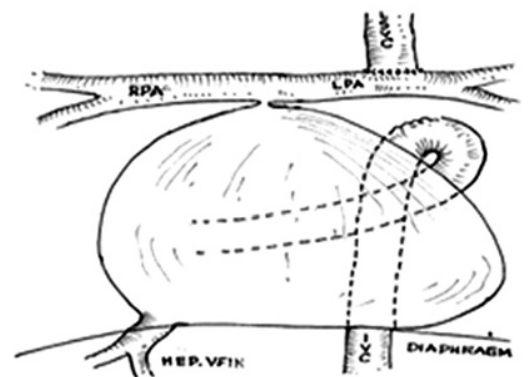

A

FIGURE 1. A and B, Kawashima completion by direct hemiazygos to left pulmonary artery connection and extracardiac hepatopulmonary connection to the right pulmonary artery completing total cavopulmonary connection. The pulmonary trunk was interrupted. $I V C$, Inferior vena cava; $L S V C$, left superior vena cava; RPA, right pulmonary artery; LPA, left pulmonary artery; HEP. VEIN, hepatic vein. 



FIGURE 2. Angiogram showing a well-flowing left-sided Glenn shunt and inferior vena cava draining through the proximal left superior vena cava to the coronary sinus.

polytetrafluoroethylene tube extracardiac conduit (GoreTex; W. L. Gore \&Associates, Inc, Flagstaff, Ariz) with a 4-mm fenestration, thus completing the Fontan circuit. The main pulmonary artery was interrupted (Figure $1, B$ ). Her postoperative recovery was uneventful.

At 1 year's follow-up, she was asymptomatic with an arterial oxygen saturation of $96 \%$ on oral anticoagulation; echocardiography showed good Fontan flows from the left SVC, hemiazygos vein, and hepatic veins. The fenestration could not be demonstrated.

\section{DISCUSSION}

Although the classic Kawashima operation needs a second-stage procedure for hepatic vein inclusion, ${ }^{1}$ singlestage cavopulmonary connection with hepatic vein inclusion has been reported with good results. ${ }^{2}$ In Infants with less satisfactory Fontan criteria, a high-risk Kawashima procedure with fenestration has also shown good results. ${ }^{3}$

In our patient, who had fair-sized pulmonary arteries, we did a simple staging of a high-risk Kawashima procedure by doing only the superior cavopulmonary anastomosis, leaving the IVC drainage intact. We kept the antegrade flow open through a pulmonary artery band to prevent the development of pulmonary arteriovenous malformations.

Even after 10 years our patient did not have pulmonary arteriovenous malformations owing to the limited antegrade flow. ${ }^{4}$ She did not have venovenous malformations (between the hemiazygos and hepatic veins) because the hemiazygos system was not pressurized as in a high-risk
Kawashima procedure, in which it would be draining to the pulmonary circulation. ${ }^{5}$ At the time of the secondstage procedure, the hemiazygos vein could be connected to the left pulmonary artery without much technical difficulty.

To the best of our knowledge, the division of the SVC above the azygos or hemiazygos entry into the SVC to create a bidirectional Glenn shunt, first with controlled antegrade blood flow and then by a second-stage Fontan completion, has not been reported so far in the setting of Kawashima procedure. This technique allows the surgeon to plan a stepwise approach in Kawashima patients who need palliation early, avoiding pulmonary vascular overload, especially in young infants whose pulmonary vasculature may not yet be ready to passively accept the majority of systemic venous flow.

\section{References}

1. McElhinney DB, Marx GR, Marshall AC, Mayer JE, Del Nido PJ. Cavopulmonary pathway modification in patients with heterotaxy and newly diagnosed or persistent pulmonary arteriovenous malformations after a modified Fontan operation. J Thorac Cardiovasc Surg. 2011;141:1362-70.

2. Amodeo A, Di Carlo D, Grigioni M, De Santis M, Di Donato RM. Early primary Kawashima operation combined with direct hepatic vein-to-azygos vein connection: a new logical approach. J Thorac Cardiovasc Surg. 2005;129: 949-50.

3. Picarelli D, Montenegro JL, Antunez S, Perez W, Borbonet D. Modified fenestration technique for the Kawashima operation in a young Infant. J Thorac Cardiovasc Surg. 2005;129:451-2.

4. Picarelli D, Kreutzer C, Antunez S. Eight years after early primary Kawashima operation. J Thorac Cardiovasc Surg. 2011;141:1085-6.

5. Mahmoud AB, Zahrani S, Bahaidarah SA, Kouatli AA, Baslaim GM. Venovenous malformation: a common finding after Kawashima operation. Eur J Cardiothorac Surg. 2011;39:222-7. 